\title{
TEORIA DO VALOR E TRABALHO PRODUTIVO NO SETOR DE SERVIÇOS
}

\author{
Sadi Dal Rosso*
}

\begin{abstract}
Interpretações da teoria do valor trabalho encontram dificuldades em definir o papel e o lugar das atividades de serviço com relação à produção ou não de valor. Esse problema ganha magnitude na medida em que a perspectiva histórica mostra que os serviços são grandes empregadores de mão de obra na atualidade. Tradicionalmente, os serviços são entendidos como atividades não produtivas, devido ao fato, dentre outros argumentos, de que não resultam em materialização na forma de mercadorias, ou que não produzem novos valores e mais-valia. $\mathrm{O}$ objetivo deste artigo é examinar essa questão e sugerir a proposição de que certos serviços, que preenchem determinadas condições, podem ser interpretados como produtivos de valor e de mais-valia. $\mathrm{O}$ artigo examina as categorias materialidade e imaterialidade, assim como as de trabalho produtivo e não produtivo de valor, introduzindo, a seguir, critérios para distinguir trabalhos produtivos e não produtivos de valor no setor de serviços. Com isso, pretende contribuir para clarificar o entendimento da teoria do valor trabalho num terreno entrecruzado de polêmicas e de posições teóricas diferenciadas.

PALAVRAS-Chave: Teoria do Valor Trabalho. Serviços. Trabalho produtivo e não produtivo. Mais-valia.
\end{abstract}

\section{APRESENTAÇÃO DO PROBLEMA}

Na discussão contemporânea sobre transformação do trabalho, os temas da materialidade e produtividade de valores ocupam lugar de destaque entre autores, seja pela crítica que é alçada à teoria do valor trabalho (Cf. Negri, 1992; Gorz, 2003), seja pela defesa e reinterpretação dessa teoria (Cf. Antunes, 1999; Amorim, 2009). Em ambos os casos, a discussão que é muito vívida envolve terreno amplo, que vai da interpretação de elementos empíricos ao campo teórico. Está em jogo a capacidade de a teoria do valor trabalho, com suas categorias básicas - entre elas trabalho produtivo e não produtivo, tempo médio socialmente necessário, valor e mais valor -, dar conta de fenômenos gerados pela divisão social do trabalho ou estimulados pela revolução informática. Este artigo atém-se ape-

* Doutor em Sociologia. Professor do Departamento de Sociologia da Universidade de Brasília. Pesquisador do CNPq, do Grupo de Estudos e Pesquisas para o Trabalho (GEPT) e da Rede de pesquisadores sobre Associativismo e Sindicalismo dos Trabalhadores em Educacão (Rede ASTE). Departamento de Sociologia. Universidade de Brasília. Cep: 70910-900. Brasília - Distrito Federal - Brasil sadi@unb.br nas a uma das questões mencionadas, a saber, a análise e discussão da questão da possibilidade da geração de valor em atividades de serviços.

Com efeito, na teoria, valor é produzido e adicionado à mercadoria pelo trabalho socialmente necessário naquele momento histórico e dentro das condições tecnológicas médias vigentes. A esfera da produção torna-se, pois, o momento crucial para o entendimento da geração do valor. Para que o valor seja realizado, a mercadoria necessita percorrer seu circuito completo, da produção ao consumo. Nas esferas de circulação, distribuição e consumo, a teoria é clara em estabelecer que valor não é produzido, e sim redistribuído. Assim, o trabalho em atividades comerciais e atividades que permitem o consumo das mercadorias não produz novos valores, somente permite a circulação e a realização de valores já criados. O trabalho em atividades do setor primário e do setor secundário da economia é, pois, elemento crucial para a concepção do valor. Entretanto, a divisão social do trabalho desloca trabalhadores das atividades primárias para secundárias e para terciárias. As atividades primárias saciam as necessidades das pes- 
soas, entre as quais as de alimentação, enquanto as do setor secundário ampliam muito o horizonte das necessidades básicas para os desejos impulsionados pela fantasia, o que amplia as fronteiras para a acumulação de capital. As atividades de serviços compreendem um conjunto muito grande de ações que possibilitam a circulação e o consumo, além de um conjunto enorme de outras atividades a elas agregadas e de natureza diversa. $\mathrm{O}$ chamado setor de serviços cresce significativamente como empregador de mão de obra. Sirva a distribuição setorial do emprego no Brasil como ilustração. Segundo a classificação empregada pelo Instituto Brasileiro de Geografia e Estatística (IBGE) no censo de 2000, tem-se que o setor primário é responsável pelo emprego de $18,7 \%$ da força de trabalho de 10 anos ou mais de idade no conjunto do país, a indústria por $21,4 \%$ e os serviços por $59,8 \%$. Se aplicada "diretamente", tal classificação para definir trabalhos que produzem valor, $40 \%$ da população estaria empregada em atividades produtivas e $60 \%$ em atividades não produtivas. O padrão de grande emprego em atividades de serviço não ocorre somente no Brasil como talvez na maioria dos países do mundo. Esses números apontam, pois, para uma dificuldade da Teoria do Valor Trabalho, de que a produção de valor envolveria menos de metade da população empregada, o que poderia ser interpretado que se está em vias de uma sociedade pós-valor. Não parece ser esse, entretanto, o caminho. Não se estaria forçando uma interpretação de que todos os serviços se situam na esfera da circulação e são, por isso, improdutivos? Não seria possível repensar essa questão do trabalho produtivo e improdutivo no setor de serviços, de tal modo a conceber mercadorias produzidas nas atividades de serviços e não necessariamente enraizadas em formas materiais e físicas?

Para encontrar uma resposta à dificuldade acima apontada, o esquema a ser utilizado no ensaio compreende expor sucintamente uma interpretação das categorias teóricas de a) materialidade, b) trabalho produtivo, e c) analisar as condições teóricas para conceber alguns serviços como produtivos e outros como não produtivos de valor.

\section{TRABALHO MATERIAL E IMATERIAL}

A categoria de materialidade está presente nas obras de Marx no período da formação de sua concepção geral da história, que abrange A Ideologia Alemã e os Early Writings, segundo o título expressivo de Tom Bottomore (1963). A noção de materialidade é o principal instrumento de crítica à elaboração filosófica idealista de Hegel (2008). Não são poucas as condenações aos equívocos filosóficos de Hegel que representam uma visão invertida de mundo, por colocar os seres humanos de cabeça para baixo. No idealismo hegeliano, a pedra angular sobre a qual se constrói sua visão de mundo é a razão, o espírito. O espírito universal se exterioriza através da cultura e da civilização. É a fenomenologia do espírito. A história é o lugar da realização do espírito. Hegel parte do céu para chegar a terra. A crítica a Hegel estabelece seu fundamento de concepção do mundo na noção de materialidade. Os seres humanos são e existem como seres vivos que dependem da natureza (Cf. Marx; Engels, 1996). Tal entendimento concebe os seres humanos não como contrapostos à natureza, mas como seres humanos-com-a-natureza. Esse elemento muito moderno (Prigogine, 1984) de concepção da relação dos seres humanos com o universo procede de um entendimento no qual os seres humanos dotados de inteligência e razão constituem o ápice da evolução da matéria organizada, entendimento que vincula o ser humano não só ao Planeta Terra como também ao universo no qual ele ocupa um pequeníssimo ponto perdido. Se Hegel (2008) constrói sua visão de mundo a partir do espírito absoluto como início e fim da história, Marx a edifica a partir da materialidade, da matéria organizada, dos seres vivos em ação. A materialidade, contraposta à razão ou ao espírito, como elementos fundantes da concepção do mundo, é categoria basilar na elaboração originária de Marx. Ela exerce papel relevante nas críticas e nas construções marxianas posteriores. Ela é fundamental para a crítica ao direito de propriedade e para a reivindicação de que os bens sejam comuns ou socializados de maneira igualitária entre todos. 
A propriedade das terras e dos capitais não são senão usurpações a que estão submetidos os mais fracos. Nessa mesma direção, a noção de materialidade está presente na construção da teoria do valor trabalho. A unidade básica da acumulação de capital é a mercadoria. E a mercadoria é um objeto que satisfaz necessidades objetivas e desejos da mente e da fantasia.

Hoje em dia, uma parte da literatura filosófica e sociológica retoma a categoria imaterialidade. Os termos empregados no embate filosófico são de idealismo, ideias, espírito, espírito absoluto, razão, razão universal. O emprego da categoria não é exatamente em sua concepção filosófica de contraposição do ideal ao material. Antes, a discussão toma o sentido de trabalho imaterial, pensado como emprego em atividades de serviço. Tem a ver com a teoria do valor trabalho e não com a categoria filosófica de imaterial contraposta ao idealismo. Duas vertentes, das quais se originaram os problemas contidos na discussão sobre imaterialidade nos dias de hoje, serão abordadas neste ensaio. Bastante distintas entre si, as vertentes apontam para um mesmo fenômeno social. A mais antiga delas é representada pela tradição econômica e sociológica anglo-americana de análise da assim chamada composição setorial da força de trabalho. A mais recente está representada pela crítica filosófica à insuficiência da teoria do valor trabalho, centrada sobre mercadorias essencialmente imateriais, para cuja produção a noção de tempo médio socialmente necessário não mais responderia às exigências da imaterialidade.

A tradição anglo-americana opera basicamente com a noção de alocação ou distribuição setorial da força de trabalho empregada. Como pode ser definida, dividida, classificada a força de trabalho? Pela alocação dos trabalhadores em setores de atividade econômica, tão homogêneos entre si quanto possível e suficientemente distintos uns em relação aos outros. A classificação não obedece, pois, a critérios arbitrários, antes procede a partir de separações criadas pelo próprio processo de divisão social do trabalho sobre o qual economistas e sociólogos clássicos tanto escreveram. Muito antes de C. Clark (1940), já se falava de população ocupada na agricultura e na indústria, sendo essa divisão entre indústria e agricultura o resultado de um processo em que a agricultura foi submetida à lógica da produção industrial. Ao ser construída, a classificação trissetorial (primário. secundário e terciário; ou agricultura, indústria e serviços) serviu de modelo também para as agências de coleta de dados, bem como manteve-se presente nas discussões econômicas e sociológicas. A observação empírica da distribuição setorial da força de trabalho permitiu deduzir dois modelos distintos de transformação, pelo menos. O primeiro, em que a força de trabalho passava de uma fase eminentemente primária para uma ocupação majoritariamente industrial e daí para a ocupação em serviços, fenômeno que começou a ser percebido já nos anos 1950 e que descreve relativamente bem a experiência histórica vivida pelos países capitalistas mais antigos e mais ricos, localizados proximamente aos centros do império mundial. Já nos países periféricos e submetidos, países de capitalismo tardio, alguns dos quais alcançaram sua independência somente no século XX, observou-se que seguiam outro modelo de transformação, que passou a ser entendido como próprio de sua condição subdesenvolvida e ex-colonial. De composição inicial eminentemente agro ou mineral-exportadora, esses países saltaram para a condição de emprego de sua mão de obra majoritariamente nos ramos de serviços. Saltam a fase de ocupação majoritariamente em postos de trabalho industrial e constituem os serviços como grandes empregadores de sua força de trabalho. Sabe-se que muitos desses serviços constituem postos de emprego deteriorados qualitativamente, e que essas multidões, que, a partir dos anos 1950, passaram a buscar habitação e trabalho nas cidades, transferiu sua miséria para os centros urbanos.

Estudos que têm como pano de fundo esses dois modelos de transformação setorial da força de trabalho foram levados a termo em muitos países, entre os quais os Estados Unidos (Bell, 1973; Browning; Singelmann, 1975; Fuchs, 1968), a França (Touraine, 1975), a Itália (Olagnero, 1982) 
e o Brasil (Dal Rosso, 1978). Os processos de transformação setorial da ocupação da mão de obra, o fato da concentração majoritária do emprego em atividades de serviços, assim como propostas as mais diversas de classificação da distribuição da mão de obra por setores de atividade constituem objetos presentes em quase todos os estudos. Que são serviços? Nesse ponto, principia uma infindável discussão conceitual que se estende até os dias de hoje, sem o encontro de uma solução consensual para o que são serviços, sua natureza, seus papéis como empregadores de mão de obra e, para os objetivos deste artigo, como se relacionam serviços e produção de valor. Que serviços são trabalhos não cabem dúvidas. A definição, entretanto, é abstrata e geral. Serviços não são atividades que produzem bens materiais, necessariamente. Mas é possível pensá-los como produtores de mercadorias de tipo imaterial? Fuchs tratou-os como atividades não tangíveis. Outros reservam simplesmente a expressão serviços para entender o emprego global em atividades que não são industriais nem extrativistas (Olagnero, 1982; Almeida, 2005). Serviços foram interpretados pelos autores das mais diversas maneiras. Bell (1973) entendeu a transição para o setor de serviços a partir da forte expansão das universidades e do sistema educacional e de pesquisa como a via para a sociedade da inteligência, certamente uma exacerbação do modelo norte-americano observado em direção a um padrão mundial. É comum a todas as perspectivas o entendimento de que a força de trabalho que opera no setor industrial está se reduzindo nos países capitalistas e que a alocação setorial da força de trabalho concentra-se nas atividades de serviço. Podese pensar que a concentração do emprego em atividades de serviço seja base para a rediscussão da teoria dos movimentos sociais e de classes. Kon (1999) realiza uma crítica severa de conceitos e tipologias empregados nas classificações das atividades de serviços. O argumento principal é que a natureza dos serviços sofreu transformações, o que forneceria base para mudar definições e classificações. Cita um esforço de modernização dessa classificação com base na "produção dentro do con- texto de um sistema interativo de oferta e demanda” (Kon, 1999, p. 80), no qual as principais funções que deveriam ser mantidas seriam a manufatura, a circulação, a distribuição e a regulação. $\mathrm{O}$ sistema proposto não parece ter ganhado a simpatia dos organismos produtores de dados estatísticos, que continuam a operar com sistemas diferenciados de definição e classificação. Se importantes relativamente à questão da interação entre esferas da economia, as críticas de Kon não auxiliam no tocante à discussão da produção ou não de valor em serviços, objetivo maior deste ensaio.

A segunda vertente do debate contemporâneo sobre imaterialidade é representada pela produção filosófico-sociológica, que se baseia, por um lado, no impacto devastador das mudanças tecnológicas da assim chamada revolução informática sobre a estrutura de produção e de serviços e, por outro, na crítica de supostos limites inquestionáveis da teoria do valor trabalho (Antunes, 1999). Os limites da teoria do valor trabalho seriam atingidos no momento em que os trabalhadores deixassem de ser produtores diretos de valor. Quando a produção de mercadorias não exigisse mais o concurso do trabalho humano, estaria alcançado o limite e a teoria cessaria de se aplicar. É na contemporaneidade que o impacto da tecnologia e da inovação se faz sentir com força máxima. Entretanto, nem hoje tal limite pode ser imaginado como atingido, por uma simples razão. Mais do que nunca, a acumulação capitalista emprega tanto trabalho humano. Como imaginar que o trabalho não é mais utilizado quando, como se sabe, todos os dias, nada menos do que dois bilhões e setecentos milhões de pessoas (Lee; McCann; Messenger, 2009) de todos os cantos do mundo levantam-se e dirigem-se a seus postos de trabalho, aí permanecendo oito horas diárias ou mais no cativeiro do labor, produzindo valores. Como então supor que a produção de mercadorias não requer mais o concurso do trabalho? Os Grundrisse contêm um capítulo em que Marx (1973) escreve que o fim da teoria do valor trabalho seria alcançado quando os trabalhadores deixassem de ser produtores diretos para serem 
controladores de máquinas. A condição dos trabalhadores como controladores de máquinas certamente se realizou, pois um dos pilares do toyotismo consiste em trabalhadores controlarem diversos equipamentos operando simultaneamente e realizando tarefas diferentes. Mas a produção do valor não cessou, porque, a despeito da mediação das máquinas, os trabalhadores continuam produzindo diretamente bens e especialmente serviços com a aplicação de seu trabalho vivo. Tal avanço civilizatório a sociedade mundial ainda não alcançou. A teoria do valor trabalho estaria em jogo se não fosse capaz de oferecer elementos conceituais para interpretar uma sociedade em que a força de trabalho está majoritariamente empregada em serviços. Serviços de toda a ordem passaram a ser os loci de empregos da grande maioria dos trabalhadores assalariados. Coloca-se, pois, a questão: os serviços são produtivos de valor ou improdutivos? Pensar o conjunto dos serviços como improdutivos decorre de uma visão de que somente a atividade que resulta em alguma forma de materialização da mercadoria é produtiva. Com isso, confina-se o trabalho produtivo às esferas do emprego no setor primário e secundário, o que parece ser um problema.

Negri e Lazzarato (1990) expandem a noção de imaterialidade para muito além dos meios comunicativos, informativos e de propaganda, que se realizam no terreno da circulação das mercadorias, e compreendem a imaterialidade como a produção da subjetividade. A produção da subjetividade está, em alguma medida, sujeita à esfera do capital. Existem outras situações de produção da subjetividade que estão completamente fora do âmbito de controle do capital. Seria o caso da produção e circulação de conhecimentos populares, que não é controlada pelo capital. É uma concepção que mantém alguma semelhança com a concepção de ‘mundo vivido' da Escola de Frankfurt. As esferas sujeitas à racionalidade instrumental, controladas pelo poder político e pela moeda, opõem-se ao mundo da vida, onde é produzida a subjetividade e, especialmente, a comunicação afetiva.

Gorz (2003) é figura polêmica. Seu Adeus ao proletariado não constitui apenas resultado de constatações empíricas, como a maioria dos estudos realizados sobre a transformação da alocação setorial da força de trabalho, mas uma crítica profunda do conjunto da teoria marxista. Seu livro recente, O Imaterial, representa um descolamento do espírito de Adeus ao Proletariado e pode ser interpretado até mesmo como um passo ao reencontro com Marx. Gorz (2003) bebe em Negri e concebe igualmente a imaterialidade indo para além dos controles do capital. A imaterialidade representa, por exemplo, o papel dos conhecimentos agregados dos quais, necessariamente, qualquer pesquisador usufrui gratuitamente e que são preservados por grupos ou pelo conjunto da sociedade. A noção aplica-se para outras esferas como a da comunicação, dos conhecimentos populares, da cultura, da socialização, da formação de grupos. Gorz (2003) dá o mesmo passo que Negri quando fala da produção da subjetividade. E, da mesma maneira que aquele, constata que a imaterialidade avança para bem além do que o capital consegue controlar. Com o que visualiza dois cenários futuros possíveis. Um em que os cidadãos conseguem controlar a expansão do capital e manter as esferas de produção da imaterialidade livres dos controles do capital. E o outro em que toda a produção da imaterialidade recai sob o controle capitalista, quando imagina o mundo como uma espécie de Matrix gigante, um Inferno de Dante. A categoria de imaterialidade conduz Hardt, Negri, Lazzarato, Gorz, Cuoco a captarem elementos da imaterialidade não apenas nos setores de atividades chamados serviços, em que se coloca a questão da produção do valor e, consequentemente, do trabalho produtivo e do não produtivo, como também de produção de valores, de conhecimentos populares, produção de subjetividades, sociabilidades etc., entendidos como elementos comuns aos participantes da aventura terrestre. A crítica maior desses autores parece provir da noção da imaterialidade da mercadoria, que não estaria sujeita à medição pelo tempo médio socialmente necessário. Uma crítica sistemática, profunda e recente a respeito de imaterialidade e subjetividade 
e suas implicações para o plano político é encontrada no pequeno livro de Amorim (2012), Valortrabalho e imaterialidade da Produção nas Sociedades Contemporâneas, e sobre a economia política do imaterial em Prado (2006). Fragilidades adicionais da crítica à teoria do valor trabalho são indicadas abaixo, ainda que, sem maior desenvolvimento. Em primeiro lugar, toda a mercadoria, por mais que se revista da forma de bem material, sempre procede do trabalho humano em sua totalidade, a saber, envolvendo capacidades físicas, mentais e afetivas. Dessa forma, não seriam apenas as mercadorias, que têm mais conteúdo imaterial, que estariam sujeitas à restrição da mensuração do tempo médio, e sim todas as mercadorias. Dessa forma, a teoria do valor trabalho, em si mesma, não seria possível. Em segundo lugar, o trabalho humano continua sendo demandado intensamente, conforme foi indicado anteriormente pelo número de bilhões de pessoas envolvidas diariamente no labor, exatamente nos dias de hoje, quando a modernidade e a inovação tecnológica atingem seus pontos mais elevados. Em terceiro lugar, a medida do tempo médio socialmente necessário continua sendo empregada como critério para remuneração de salários no mercado capitalista. Em quarto lugar, a análise da duração da jornada de trabalho, em todo o mundo, permite estimar o trabalho excessivo (trabalho para além de 48 horas semanais) na proporção de $22 \%$ das pessoas que trabalham (Lee; McCann; Messenger, 2009, p.55), convalidando a importância da duração da jornada e do tempo médio socialmente necessário. Em quinto lugar, o trabalho imaterial é entendido como se fosse um labor de natureza diversa em relação ao trabalho material. Como se o trabalho imaterial somente consumisse energias espirituais do trabalhador. Mas o trabalhador é um ser uno. Em todos os tipos de labor, ele despende energias físicas, intelectuais e afetivas. Em sexto lugar, o trabalho em atividades de serviços e o trabalho imaterial não são menos precarizados do que o trabalho em outras esferas do labor.

Antes de passar para o capítulo dedicado ao trabalho produtivo e improdutivo vale ressaltar uma conclusão: as categorias materialidade e imaterialidade têm incidências sobre a formulação da teoria do valor trabalho. Desde a enunciação originária da teoria, a mercadoria jamais foi compreendida como bem material, físico, apenas. Mercadorias são produzidas para saciar necessidades materiais ou para atender a desejos da fantasia (Marx, 1975). Desejos do espírito, que não são aportes da modernidade e são encontrados em todos os momentos da história humana, podem ser também mercadorias, atendidas certas condições.

\section{TRABALHO PRODUTIVO E NÃO PRODUTIVO}

O tema do trabalho produtivo e do trabalho não produtivo aparece em muitos lugares na obra de Marx, dos quais dois textos são fundamentais. O primeiro contém um tratamento histórico crítico e está contido no primeiro volume das Teorias da Mais-Valia (Marx, 1977) e que, em razão de ser uma discussão da literatura, não será analisada nesta contribuição. O segundo tratamento ao tema é de ordem conceitual e está contido no chamado Capítulo Inédito do Volume I de O Capital. Nesse texto, Marx procura trabalhar conceitualmente e com mais detalhes o tema do trabalho produtivo e do trabalho não produtivo. Amorim (2009, p.5358) realiza uma análise profunda do Capítulo Inédito. Encabeça o texto com o título "Produção Industrial e Serviços, Trabalho Produtivo e Improdutivo", estabelecendo subliminarmente uma relação simétrica entre os termos. Interpreta trabalho produtivo e improdutivo dentro do sistema produção social em seu conjunto: "Nesse processo de produção social, alguns trabalhadores mais ligados aos instrumentos manuais de produção, aos meios de trabalho em geral, e outros mais ligados a trabalhos cognitivos cooperam para que a produção se desenvolva cada vez mais [...]”. E conclui, empregando a mesma estratégia argumentativa de simetria e relação entre os termos: "Nas várias formas de trabalho abstrato há aqueles que produzem mais-valia e aqueles que reproduzem/fazem circular a mais-valia - são respectivamente traba- 
lho produtivo e trabalho improdutivo". Uma interpretação coerente que se destaca por facultar implicações políticas imediatas.

O chamado capítulo VI Inédito (Cf. Marx, 1978) trata do trabalho produtivo e não produtivo na primeira parte, intitulada "Resultados do Processo Imediato de Produção, em que a produção capitalista é entendida como produção da mais-valia”. Nessa primeira parte, as duas questões importantes tratadas são a subsunção formal e a subsunção real do trabalho ao capital. Somente após tal esclarecimento conceitual da transição da subsunção formal para a subsunção real é que Marx parte para aprofundar o tema do trabalho produtivo e do trabalho não produtivo. Dez páginas é o espaço que dedica ao esclarecimento dessas questões.

Inicia a discussão pontilhando firmemente a noção de trabalho produtivo. "É produtivo o trabalhador que executa o trabalho produtivo, e é produtivo o trabalho que gera diretamente maisvalia, isto é, que valoriza o capital" (Marx, 1978, p.71). O critério para o trabalho ser produtivo é gerar diretamente mais-valia. Com esse tratamento, Marx retira duras conclusões. A primeira refere-se à subsunção real. Dentro da subsunção real, os vários agentes do processo direto de trabalho são entendidos como trabalhador coletivo: é o caso do diretor, do engenheiro, do técnico, do capataz. Ainda que eles não sujem suas mãos com graxa, são produtivos na medida em que fazem parte de um grupo, o trabalhador coletivo. A segunda conclusão é de que não basta ser trabalho assalariado para ser trabalho produtivo. Há que produzir diretamente mais-valia. Se o trabalhador é assalariado, mas não produz diretamente mais-valia, não aumenta o valor produzido pelo trabalho e apropriado como mais-valia, não é trabalho produtivo. A partir desse ponto, Marx começa a analisar um tema espinhoso, que até os dias de hoje provoca a maior discussão e as maiores divergências. Desde sua época, os serviços constituíam um setor em que parte da força de trabalho labutava.

Em princípio, para Marx, o trabalho nas atividades chamadas de serviços é improdutivo. A razão para essa afirmação consiste na relação construída, que é uma relação entre trabalho trocado por dinheiro e não trabalho trocado por capital. Os serviços permanecem no nível de valores de uso. São consumidos como valores de uso e não como valores de troca. Não respondem ao critério de produzir diretamente mais-valia. "Por conseguinte, não são trabalhos produtivos e seus executantes não são trabalhadores produtivos" (Marx, 1978, p.73). Com esse argumento geral, a questão parece estar encerrada para Marx. Os serviços são trabalhos improdutivos e ponto final. Entretanto, o problema é mais complexo. Não existiriam serviços que poderiam ser concebidos como produtivos? Não existiriam trabalhos imateriais que poderiam ser compreendidos como produtivos? Todos os serviços seriam inexoravelmente improdutivos, no sentido de não valorizarem o capital? Como o assunto é espinhoso, Marx estende a discussão por várias páginas, tentando resolver o problema de ordem conceitual e teórica. Constitui um exercício instigante seguir os passos do argumento. Convido os leitores a seguir a trilha da discussão.

O filósofo traz para o foco da discussão várias atividades "envoltas outrora por uma auréola" (Marx,1978, p.73) e que, como tal, eram exercidas gratuitamente ou pagas indiretamente, no contexto histórico da Inglaterra. Entre elas, "os profissionais, os médicos, os advogados", que mais tarde passaram a ser remunerados em salários. Sua lista é maior e compreende inúmeras atividades que vão “desde a prostituta até o rei”, passando pela figura do soldado, como escreve desafiadoramente. Essas atividades não constituem trabalho produtivo, porque nelas os trabalhadores simplesmente "trocariam serviços por dinheiro". Estariam em relação de assalariamento, e não propriamente de trabalho produtivo para o capital. Aqui há espaço para uma boa discussão, uma vez que o argumento de Marx está limitado ao contexto da Inglaterra de sua época. Muitas dessas atividades profissionais - entre as quais o exercício da medicina, da odontologia, das engenharias, o trabalho dos químicos, dos biólogos, dos advogados - foram proletarizadas, isto é, passaram a ser exercidas por empresas que buscam aumentar a valorização do 
seu capital com o trabalho desses profissionais. Em tais condições, essas atividades são produtivas, porque valorizam o capital. Contribuem para a criação de mais-valia, nessas circunstâncias. Talvez, nos dias de hoje, melhor seria organizar o argumento com uma distinção. A mesma atividade profissional pode ser produtiva se organizada sob a forma de uma exploração do trabalho vivo por indivíduo ou empresa, ou improdutiva se significa simplesmente a troca de serviços por dinheiro, como acontece com muitos profissionais liberais e científicos que operam individualmente e são autoempregados. Essa dupla perspectiva já estava presente na cabeça do autor quando escreve que "um trabalho de idêntico conteúdo pode ser, portanto, produtivo e improdutivo" (Marx, 1978, p.75).

Outras situações hoje conhecidas como serviços esclarecem a aplicação dessa noção de duplicidade. Quatro casos significativos são apresentados. Primeiro, John Milton, poeta que escreveu O Paraíso Perdido, é um trabalhador improdutivo (pelo critério de valorização do capital), ainda que tenha escrito uma obra genial. Já "o escritor que proporciona trabalho como de fábrica a seu livreiro, é trabalhador produtivo" (1978, p. 76). Segundo caso: como é entendido o trabalho da cantora, uma produtora eminentemente imaterial? Enquanto ela "entoa como um pássaro" e recebe remuneração por isso é trabalhadora improdutiva. "Mas a mesma cantora, contratada por um empresário, que a faz cantar para ganhar dinheiro, é um trabalhador produtivo, já que produz diretamente capital” (p.76). Terceiro caso: com o professor ocorre a mesma coisa. Desde que contratado para valorizar o dinheiro do empresário da instituição que trafica com conhecimento, "é trabalhador produtivo”. Quarto caso: atividades conhecidas como por "conta própria", segundo os critérios do IBGE, a exemplo de alfaiataria e jardinagem. Elas podem ser apenas troca de trabalho por dinheiro, condição em que o trabalho não é produtivo, ou podem ser trabalho produtivo, "por constituir um momento do processo de autovalorização do capital." (p.76). Esses quatro exemplos - do escritor, da cantora, do professor, do alfaiate e do jardineiro - proporcionam elementos que contribuem para resolver a questão dos serviços. Marx não entendia que apenas o trabalho material fosse produtivo. $\mathrm{O}$ trabalho imaterial também é produtivo desde que atenda ao critério de "gerar diretamente mais-valia”. Esclarece ainda a questão do autoemprego e as condições em que é trabalho improdutivo.

No texto, entretanto, encontra-se uma consideração que minimiza o lugar dos serviços na sociedade, as tendências futuras do emprego por setores de atividade e a capacidade de essas atividades empregatícias de serviços serem exploradas de modo capitalista. "Constituem magnitudes insignificantes se comparados com o volume da produção capitalista. Por isso, se deve fazer caso omisso desses trabalhos, e tratá-los somente a propósito do trabalho assalariado, sob a categoria de trabalho assalariado que não é ao mesmo tempo trabalho produtivo" (1978, p. 76). Essa consideração, apresentada imediatamente após distinguir, de maneira esclarecedora, em que situação um trabalho profissional é produtivo e em que condição é improdutivo, pode ser atribuída ao contexto da época, isto é, à pequena importância do setor de serviços na alocação dos empregos e na geração do produto total. Hoje em dia, o trabalho em serviços compreende a maior parte dos empregos das economias centrais e periféricas, não podendo, portanto, ser pensado como "caso omisso".

O último ponto colocado para apreciação dos participantes desta discussão refere-se ao tratamento da questão da imaterialidade e da produtividade. Ela é analisada com uma linguagem ríspida. Chama de "mania" a forma de definir o trabalho produtivo segundo seu conteúdo material (Marx, 1978, p. 73). Como foi dito anteriormente, o critério definidor do valor do trabalho consiste na capacidade de "gerar diretamente mais-valia", e não na materialidade ou imaterialidade do conteúdo ou do produto. A "mania" de ver a produção do valor somente nos trabalhos com conteúdo material adviria de uma concepção fetichista que considera a qualidade de ser produtivo como decorrência inerente aos repositórios materiais dessas determinações, de uma concepção segundo a 
qual só é produtivo o trabalho que resulta em um produto material e da consideração da relação que está em voga. Se de um alfaiate se compra a calça ou seu serviço, "isto me é totalmente indiferente" (1978, p. 78). O que importa é verificar se a relação é de troca simples de serviço ou objeto por dinheiro, ou se de trabalho que visa a aumentar o valor do capital. "A diferença entre o trabalho produtivo e o improdutivo consiste tão somente no fato de o trabalho trocar-se por dinheiro como dinheiro ou por dinheiro como capital" (p. 79).

A análise da produção não material é difícil até os dias de hoje. As atividades de serviço podem ser vistas de muitos ângulos e segundo muitas de suas características. Uma das questões, por exemplo, é se os chamados serviços são atividades completamente imateriais, intangíveis. Impulsionado por esses desafios, Marx prossegue distinguindo entre situações que envolvem "mercadorias que existem isoladamente em relação ao produtor" e situações em que o "produto não é separável do ato de produção" (1978, p. 79). O primeiro caso de produção não material, mas que o produto se separa do executante, é representado pelo caso de livros, quadros e produtos artísticos. Esses casos representam formas de transição para o modo de produção apenas formalmente capitalista. O segundo caso é exemplificado pelo médico e pelo professor, e, nele, "o modo capitalista de produção só tem lugar de maneira limitada”. Em ambos, a relação capitalista encontra-se sob uma forma restrita ou representa formas de transição. Na sociedade contemporânea, já não são mais formas de transição nem limitadas. São atividades inteiramente capitalistas.

A discussão conduz ao seguinte entendimento: as atividades desenvolvidas nos setores de serviços são improdutivas quando organizadas de maneira a trocar serviços por remuneração, mesmo que envolvendo algum substrato material, como livros, quadros, obras de arte, softwares; e são produtivas, quando organizadas como meio para ampliar o capital inicialmente investido. Essa compreensão rasga o "setor" de serviços em duas partes: uma não produtiva, outra produtiva. A próxi- ma sessão discutirá critérios para o estabelecimento de condições para um e outro caso. A concepção assim estabelecida garante uma coerência com o fenômeno social do emprego em serviços, assim como com a necessidade de uma teoria que garanta papel explicativo para a maioria dos casos considerados.

\section{TRABALHO PRODUTIVO E NÃO PRODUTIVO EM SERVIÇOS}

Há formulações que consideram os serviços como marginais no conjunto das atividades do mundo capitalista. A chamada teoria da marginalidade contém, em alguma medida, esse viés. Conquanto ela acentue a desigualdade e a precarização, dificulta o entendimento da alocação da mão de obra. Não pode ser chamado de marginal um setor que ocupa mais de metade da população em condições de atividade. O censo demográfico do ano 2000, no Brasil, dá conta de que $60 \%$ da população em idade ativa efetua seu labor diário em serviços. Ferreira e Velloso (2013, p. 144) operam com informações ainda mais recentes, segundo as quais a percentagem das pessoas ocupadas em serviços alcançaria $63 \%$ das pessoas ocupadas em 2005, no Brasil. Tendência semelhante de crescimento continuado da proporção de emprego em serviços pode ser verificada no censo de 2000. Os autores apresentam ainda uma tabela mais ampla da evolução do emprego entre 1950 e 2005. A absorção da mão de obra pela indústria mantém-se praticamente constante em torno do patamar de $20 \%$. A percentagem de emprego na agricultura e em outras atividades primárias cai do patamar de $62 \%$ para $19 \%$ do emprego da mão de obra, enquanto a ocupação em serviços faz um movimento inverso, alçando-se da percentagem de $20 \%$ para $63 \%$, no mesmo intervalo. O entrecruzamento da linha de empregos na agricultura e da linha de ocupação em serviços teria ocorrido em torno a 1975, quando era vigente a política econômica desenvolvimentista do regime militar, que acentuou vigorosamente a modernização e a capitalização das atividades extrativas e do rural, resul- 
tando em massivos deslocamentos migratórios, com expulsão de trabalhadores do campo para a cidade.

O Brasil realizou a transição da predominância do emprego no setor primário para o emprego no setor terciário sem conhecer a experiência de transformar-se em sociedade industrial, segundo o critério de percentagem de empregos. Esse tem sido também o destino da maior parte das sociedades subdesenvolvidas, nela incluídos países da América Latina, da África e de boa parte da Ásia. Nessa conta, precisam ser acrescidas ainda as nações industrializadas de capitalismo tardio. Tudo somado, tem-se como resultado uma proporção muito grande da população mundial laborando em atividades classificadas pelas agências estatísticas como serviços. Esses dados expõem uma dificuldade para a interpretação da teoria do valor trabalho se os trabalhos no setor de serviços forem concebidos globalmente como não produtivos.

Cabe, então, reexaminar as classificações não a partir das coerências intrínsecas a setores, ramos e grupos de atividades, mas considerando pressupostos da teoria do valor trabalho. A teoria do valor trabalho foi construída para analisar criticamente o sistema capitalista, em que a força de trabalho é assalariada (Marx, 1975). O entendimento do sistema dá-se por meio das categorias de mercadoria, valor e mais-valor, pelas quais o resultado do trabalho pode ser maior do que os gastos efetuados com pagamento da força de trabalho, dos meios, instrumentos, matérias primas etc. necessários à produção de uma mercadoria. Torna-se crucial, pois, para a teoria do valor trabalho, distinguir atividades produtivas de atividades não produtivas no conjunto da economia e da sociedade. Importa ressaltar que o debate sobre trabalho produtivo e não produtivo e o debate sobre classificações de alocação setorial laboral são de natureza inteiramente diversa. A teoria do valor preocupa-se com as categorias de valor e mais valor. As classificações censitárias da alocação setorial da força laboral buscam responder aos princípios de homogeneidade e de interdependência das atividades. Admitida a diversidade da natureza de cada campo de discussão, cabe aprofundar a discussão sobre mercadoria, valor e mais-valia, quando relacionada ao setor de serviços.

A literatura é fortemente inclinada a assumir a tese de que o grande setor de serviços é composto centralmente por atividades não produtivas, interpretação que apresenta o problema de explicar um sistema que se baseia sobre um alicerce reduzido, se empregada a distribuição da força laboral como critério. Assim, no caso brasileiro acima indicado, a força de trabalho estaria com $60 \%$ de seu espaço de emprego ocupado em atividades não produtivas, segundo o critério de valor. Em países onde os serviços ocupam maiores espaços, essa proporção pode manifestar-se ainda superior. E como há uma tendência no sentido de migração da inserção laboral para atividades de serviço, o problema apresenta perspectivas de se agudizar ainda mais.

Como os critérios empregados pela teoria do valor trabalho e pelas classificações censitárias de atividades não são equivalentes, há que aprofundar a discussão no sentido de discutir se todas as atividades de serviço devem ser consideradas como não produtoras de mais valia, ou se não haveria atividades, ditas de serviço, que são produtivas de valor. Essa discussão ganha sentido, entre outros argumentos, a partir da divisão social do trabalho implementada pela política neoliberal recente na economia. Um primeiro argumento consiste no fato de que o neoliberalismo promoveu uma transformação estrutural das empresas, expulsando de dentro das fábricas atividades que, fazendo parte da rede produtiva, ainda assim podiam ser terceirizadas. Esse argumento não deve conduzir à aceitação da ideia de que todas as atividades terceirizadas, de fábricas ou de empresas primárias, sejam produtoras de valor. Há aquelas que são e aquelas que não são produtivas.

Cabe ainda indicar que o movimento de ascensão do emprego no setor de serviços começou antes da vigência das políticas neoliberais, iniciadas a partir de meados da década de 1970. O problema reside, essencialmente, em saber em que se assenta a produção da mais valia. Não basta, por conseguinte, viger o sistema de assalariamento. É imprescindível distinguir o papel da atividade na 
cadeia da produção do valor. Pergunta-se, então, se somente as atividades que se materializam em mercadorias produziriam valor. Esse critério parece excessivo, pois há mercadorias que não se materializam imediatamente. Assim, cantores, quando se apresentam em shows e programações, somente produziriam valor no momento em que suas músicas se materializassem em DVDs, CDs ou em outras formas de mercadorias transacionáveis. No caso de shows musicais, atividades teatrais, óperas, balés, danças e outros tipos de apresentações artísticas, quando realizadas sob a forma empresarial, havendo a produção e a circulação de mercadorias que exigem a presença simultânea do produtor e do consumidor, parece excessivo que não sejam compreendidas como produtivas de valor. As "indústrias” da música, dos concertos, das artes cênicas, produzem mercadorias, não apenas quando materializadas em suportes físicos, mas também quando a arte mercadoria circula dos produtores aos consumidores em performances diretas.

O problema enfrentado é se alguns serviços podem gerar mercadorias e valor. Na busca de uma solução, importa ressaltar que a discussão se refere à possibilidade de alguns serviços produzirem mercadorias que circulam pelo espaço econômico, perfazendo o circuito de produção, circulação e consumo, como é próprio das mercadorias. Rubin (1972, p. 69) escreve: “[...] valor 1) é uma relação social entre pessoas, 2) que assume uma forma material e 3) está relacionado ao processo de produção".

Serviços produzem mercadorias, valor e mais valia quando estiverem presentes as condições de serem executados por trabalho assalariado contratado, com o fim de realizar ganhos e se, por meio do trabalho, houver produção e circulação de mercadoria de tal modo que o valor se realize, resultando em mais valia que pode ser apropriada pelos contratadores ou por outras agências do capital. Há serviços que se materializam imediatamente em produtos, o que torna mais fácil o reconhecimento da presença de mercadorias, de valor e de mais valor, por assumirem uma forma material, na expressão de Rubin (1972). Em belas artes, pintura, escultura, desenho, arquitetura, fotogra- fia e cinema apresentam separadamente a fase da produção e do consumo, completando claramente o processo de comodificação. O circuito de produção, circulação e consumo coloca-se como necessário para que a obra de arte passe pelo mercado e realize, assim, seu valor. Outros não, pois produção, circulação e consumo realizam-se ao mesmo tempo, como é o caso de shows, apresentações musicais e teatrais, balés, danças, as artes de performance e outras modalidades artísticas. A produção simultânea à circulação e ao consumo não impede que o serviço seja entendido como produtivo de valor, uma vez que importa a presença do trabalho assalariado, da mercadoria e da mais valia. Os esportes constituem outras atividades de serviços em que existe a possibilidade de materialização da mercadoria ex post, sem deixar de se estabelecer um processo completo de mercadorização também durante a performance.

Agrupamentos de atividades em que os serviços apresentam a característica de produção de mercadoria, com a possibilidade da apropriação de mais-valia, mereceriam acurados estudos específicos e poderiam incluir, entre outros: reparação de veículos automotores; conserto de objetos pessoais e domésticos; alimentação e restauração; transporte, armazenagem e comunicação; alguns serviços prestados a empresas, tais como internet e rede de comunicações; educação, saúde e outros serviços exploradas privadamente, como fornecimento de energia, telefone, abastecimento de água, limpeza e coleta de lixo (Cf. Dowbor, 2006); e serviços coletivos, como cultura, arte, esporte e outros serviços apresentados acima nesta comunicação.

Se todos os serviços forem entendidos como faux frais tão somente, ergue-se um imenso obstáculo metodológico e conceitual, a partir do qual o capitalismo assentar-se-ia sobre uma pirâmide invertida dos agentes de produção do valor. Seriam os trabalhadores produtores de valor proporcionalmente em número menor que os trabalhadores não produtivos? Que implicações decorrem dessa compreensão para a crítica do capitalismo nos dias atuais?

Um desses conjuntos de atividades deslocados para "periferia do sistema" é constituído 
pelos operadores de teleatendimento. São "atividades consideradas de baixo valor agregado", e ainda assim são exploradas por empresas capitalistas. Como são consideradas atividades de baixo valor agregado, o trabalho é organizado segundo a fórmula taylorista. "O trabalho do teleoperador torna-se objeto de uma regulação tecnológica [...] A base técnica proporciona a oportunidade de a empresa fixar os ritmos produtivos [...], a intensificação dos ritmos e o aumento do controle pelos supervisores e coordenadores.” (Braga, 2006, p.78). O autor considera os teleoperadores como parte da "renovação da própria condição proletária contemporânea' (2006, p.1). E vincula o processo de surgimento desses trabalhadores

[...] à desestruturação da empresa fordista em benefício de um modelo de organização das relações de produção orientado pela generalização do processo de terceirização, pela compressão dos níveis hierárquicos, pelo desenvolvimento de estratégias gerenciais objetivando a mobilização permanente da força de trabalho, pela cooperação constrangida dos assalariados, pela administração por metas, assim como pela fragmentação da relação salarial. Trata-se da empresa neoliberal [...] Por meio das terceirizações logrou-se dispersar as concentrações operárias e facilitar a destruição das 'antigas' relações políticas - além de fazer com que os novos empregos 'derrapassem' para os serviços (Braga, 2006, p. 5-6).

A questão que interessa consiste em saber se os operadores de teleatendimento são trabalhadores que produzem valor ou não. A resposta, a partir da perspectiva do setor de atividade, seria imediatamente negativa, uma vez que estão alocados entre serviços, e serviços são, a princípio, não produtivos de valor. Entretanto, a divisão do trabalho mantém vinculações entre esses setores, mesmo que classificados separadamente por agências de coletas de dados. Nessa linha de raciocínio, os serviços específicos, como os dos teleoperadores, constituem parte de um processo maior, cujas atividades “derraparam para os serviços”, na expressão do autor citado. Portanto, a pertença ao campo da produtividade ou da não produtividade depende da rede de relações econômicas na qual os teleoperadores estão envolvidos. Naquelas redes que se organizam como partes de um processo maior produtivo de mercadorias vinculadas à produção de valores, o conjunto desses trabalhadores faz parte do coletivo de um trabalhador geral produtivo. Diversamente, os teletrabalhadores que operam para empresas de circulação, comércio e finanças localizam-se em espaços apenas de circulação das mercadorias, não sendo possível convertê-los em trabalhadores industriais de valores imateriais, já que operam apenas no terreno da circulação de mercadorias. Esse critério geral faculta interpretar o problema da produtividade ou não produtividade dos serviços quanto à questão da produção de valores, em função da complexidade dos setores. A interpretação parte do pressuposto de que nem todos os serviços são improdutivos de valores. Há que separar serviços produtivos de serviços não produtores de valores segundo as redes a que se vinculam.

O critério do assalariamento é insuficiente, pois, para oferecer uma resposta satisfatória à questão da produtividade ou não produtividade de valor, porque o assalariamento prevalece também em setores que não produzem mercadorias. Assim é o caso das atividades públicas, feitas para prestação de serviços pelo Estado. O Estado não assalaria indivíduos para produzir ganhos com o labor desses servidores. Contrata-os para responder por meio de prestação de serviços públicos, gratuitos em sua maior parte, às demandas populares. Tais atividades públicas não produzem mercadorias que, vendidas no mercado, geram ganhos econômicos. Se não há mercadoria, não há valor, nem mais-valor, não cabendo, portanto, a questão do labor produtivo ou não produtivo. Obviamente, esse argumento não se aplica a situações em que o Estado reveste-se da persona de empresário, quando possui empreendimentos de exploração mineradora e empresas estratégicas, fabrica avióes e mísseis, circunstâncias em que produção de mercadorias, valores e mais valores encontra-se totalmente imbricada. O critério da produção ou não de mercadorias rasga transversalmente as atividades de serviços entre produtivos e não produtivos de valor e mais-valia. Os servi- 
ços de propriedade pública prestados pelo Estado necessitam ser distinguidos pela relação que contêm. Se os serviços prestados pelo Estado são organizados empresarialmente, de forma a gerar a relação específica de trabalho e capital que produz mais valia, como tende a ocorrer na prestação de serviços de telefonia, comunicação e correio, eles são serviços produtivos. Muitos serviços estatais não preenchem essa condição. São prestações aos cidadãos, pois o trabalho dos servidores públicos é pago por meio de um salário, e a relação extingue-se aí. Apenas prestam-se serviços de educação, de saúde pública e outros mais que dependem do grau de civilidade ou barbárie de cada nação.

\section{CONCLUSÕES COM PROPOSTA}

Os argumentos desenvolvidos ao longo deste artigo fornecem elementos para fundamentar a proposição de que o grande setor de emprego em serviços pode ser dividido de acordo com as categorias de trabalho produtivo e não produtivo de valor. Essa proposição tem largo alcance e contribui para responder a uma questão suscitada à teoria do valor trabalho, pelo fato de o setor de serviços das economias abarcar o emprego da maior parte da população em idade ativa. A teoria do valor trabalho é uma proposta em si independente de referenciais empíricos. Todavia a riqueza de uma teoria consiste em sua capacidade de permitir compreender a realidade, iluminar o social, interpretar o conjunto de relações sociais em operação.

Com vistas à sustentação da proposição de que determinados trabalhos, no setor de serviços, podem ser entendidos como produtores de valor, o texto foi organizado em três partes. Na primeira, examinaram-se as categorias materialidade e imaterialidade, importantes para pensar mercadorias não apenas como bens materiais, assim como respostas a desejos do espírito. Restringir a discussão da mercadoria à materialidade do conteúdo ou do produto representa uma concessão ao fetichismo, um hábito, uma naturalização que impede ver mais longe e mais profundamente. Seria produtivo somente o trabalho que resulta em um produto material. Se de um alfaiate se compra a calça ou seu serviço, "isto me é totalmente indiferente" (Marx, 1978, p. 78). Na segunda parte, discutiu-se o sentido geral do trabalho produtivo e não produtivo com base na literatura clássica da teoria do valor trabalho e em textos contemporâneos. E, na terceira, examinou-se a questão do trabalho produtivo e não produtivo no setor de emprego em serviços. O emprego em serviços ocupa a maior parte da população economicamente ativa, seja dos países capitalistas antigos, seja das nações de capitalismo mais recente.

A proposição de que determinados serviços são produtores de valor e outros não rasga, por assim dizer, o setor terciário da economia ao meio. Empregar o argumento do trabalhador global, do trabalhador coletivo, para resolver a questão do trabalho produtivo ou não de valores em atividades de serviços, é politicamente relevante para manter a unidade, a força de ação coletiva da classe trabalhadora, estabelecer possibilidades de relações de identidade. A estratégia não tem o mesmo efeito para resolver a questão do labor produtivo ou não. Pelo argumento do trabalhador global, todos os trabalhadores dos setores de serviços seriam classificados conjuntamente como produtivos ou como improdutivos. O entendimento sugerido neste atigo consiste em uma análise mais detalhada da questão do trabalho produtivo ou não produtivo, caso a caso, setor por setor, categoia por categoria, conforme necessário a cada situação.

Com base na literatura, foram enunciados critérios para separar e definir a divisão entre trabalho produtivo ou não no setor de serviços. Estabelece-se, de partida, que a questão atém-se ao campo das atividades assalariadas. Em segundo lugar, as mercadorias podem ter conteúdo material ou imaterial. Em terceiro, também para mercadorias geradas no grande setor de emprego em serviços, o valor é gerado na esfera de produção, e não na circulação. O trabalho em serviços que realiza apenas a circulação das mercadorias, nada acrescentando a elas de valor e mais valor, não pode ser interpretado como produtor de valor. Para ser pro- 
dutivo, o trabalho em serviços precisa gerar mais valor. Em quarto lugar, também não são considerados produtivos os labores de assalariados do Estado que prestam serviços à população. Finalmente, em quinto lugar, há trabalhos em serviços que produzem mercadorias novas ou que acrescentam valores às mercadorias, o que respalda a proposta de trabalho produtivo em determinados serviços.

A teoria do valor trabalho tem sido abundantemente empregada em estudos recentes para revelar a precarização das condições de trabalho, que se estende também ao labor no setor de serviços. Importantes na ótica da exploração laboral, estudos precisam ser levados a efeito também com a ótica do trabalho produtivo ou não de valor no setor de serviços, caso a caso, ramo a ramo, grupo a grupo.

Desenvolver a teoria do valor trabalho, nos dias de hoje, atende a necessidades reais de exploração desenfreada do trabalho. O número de trabalhadores em todo o mundo é de dois bilhões e setecentos milhões. Esse imenso contingente de pessoas, todas as manhãs, move-se para seus respectivos locais de atividade para produzir valores de que a sociedade necessita, além de permitir gigantesca acumulação de capital. Para tanto, vinte e dois por cento desses trabalhadores labutam mais de quarenta e oito horas por semana em trabalho excessivo.

Recebido para publicação em 15 de junho de 2013 Aceito em 10 de setembro de 2013

\section{REFERÊNCIAS}

AMORIM, H. Trabalho imaterial. Marx e o debate contemporâneo. São Paulo: Annablume; FAPESP, 2009.

Valor trabalho e imaterialidade da produção nas sociedades contemporâneas. Buenos Aires: CLACSO, 2012

ANTUNES, R. Os sentidos do trabalho. São Paulo: Boitempo, 1999.

BELL, D. The coming of post-industrial society. New York Basic Books, 1973

BOTTOMORE, T. Early Writings of Karl Marx. London: Watts, 1963.

BRAGA, R. Uma sociologia da condição proletária contemporânea. Tempo Social, São Paulo, v. 18, n. 1, p. 133-152, 2006 BROWNING, H.; SINGELMANN, J. The emergence of a service society: demographic and sociological aspects of the sectoral transformation of the labor force in the USA. Austin, EUA: The University of Texas, 1975 (Relatório de pesquisa).

CLARK, C. The condition of economic progress. London: Macmillan, 1940.

DAL ROSSO, S. The growth of capitalism and transformation of the labor force in Brazil.: 1978. Dissertation (Unpublished PH.D) - University of Texas, Austin, EUA, 1978.

DOWBOR, L. O que acontece com o trabalho. São Paulo: SENAC, 2006.

FERREIRA, C. F. E VELLOSO, F. O desenvolvimento econômico brasileiro no pós-guerra. In: VELLOSO, F. et al. (Org.) Desenvolvimento econômico: uma perspectiva brasileira. Rio de Janeiro: Elsevier, 2013. p. 129-166.

FUCHS, V. The service economy. New York: Columbia University Press, 1968.

GORZ, A. L’immattériel. Paris: Galilée, 2003.

HEGEL, G. W. F. A filosofia da história. Brasilia: Ed. UnB, 2008.

KON, A. Sobre as atividades de serviços: revendo conceitos e tipologias. Revista de Economia Política, São Paulo, Editora 34, v.19, n.2, p.64-83, abr./jun., 1999.

LEE, S.; McCANN, D. MESSENGER, J. C. Duração do trabalho em todo o mundo. Tendências de jornadas de trabalho, legislação e políticas numa perspectiva a global comparada. Brasília: OIT. 2009.

MARX, K. Grundrisse. Foundations of the critique of political economy. New York: Vintage books. 1973.

$\overline{1975 . \mathrm{v}} \cdot 1$ Capital. New York: International Publishers,

Teorias sobre la plusvalía. Primera parte. Barcelona: Grijalbo, 1977.

O Capital. Livro I. Capítulo VI (inédito). São Paulo: Ciências Humanas, 1978.

MARX, K.; ENGELS, F. A ideologia alemã. São Paulo: HUCITEC, 1996

NEGRI, A. Valeur travail: crise et problèmes de reconstruction dans le postmoderne. Multitides 1992. Disponível em: http://multitudes.samizdat.net/Valeurtravail-crise-et-problemes. Acesso em: 19 mar. 2013.

Marx et le travail: le chemin de la désutopie. Multitudes 1996. Disponível em: http:// multitudes.samizdat.net/Marx-et-le-travail-le-chemin-dela. Acesso em: 19 mar. 2013.

Travail et affect. Multitudes, 1997. Disponível em: http://multitudes.samizdat.net/ Travail-et-affect. Acesso em: 19 mar 2013.

NEGRI, A.; LAZZARATO, M. Travail immatériel et subjectivité, Multitudes, 1990. Disponível em: http:// multitudes.samizdat.net/Travail-immateriel-etsubjectivite. Acesso em: 20 mar. 2013.

OLAGNERO, M. Terziario e terziarizzazione nell'analisi sociológica. Milano: Franco Angeli Editore. 1982.

PRADO, E. F. S. Uma crítica à economia política do imaterial, 2006. Disponível em: www.usp.br/feaecon/ media/livros/file_78.docý. Acesso em: 12 jul 2013.

PRIGOGINE, I.; STENGERS, I. A nova aliança. Metamorfose da ciência. Brasília: EdUnB. 1984

RUBIN, I. I. Essays on Marx's theory of value. Detroit: Black and Red, 1972

TOURAINE, A. La società post-industriale. Milano: Angeli, 1975. 


\section{LABOR THEORY OF VALUE AND PRODUCTIVE LABOR IN THE SERVICE SECTOR}

\author{
Sadi Dal Rosso
}

Interpretations of the labor theory of value face difficulties in defining the role and place of service activities with relation to the production or not of value. This problem becomes even more pronounced while historic perspective shows that nowadays services are the great employers of labor. Traditionally, services can be understood as non-productive activities, due to the fact, amongst other arguments, that they are not materialized as commodities, or that they do not produce new values and surplus-value. This paper aims to examine this issue and suggest the proposition that some services that meet specific conditions can be interpreted as productive in terms of value and surplus-value. This paper examines the categories of materiality and immateriality, as well as those of productive and non-productive labor of value, then introducing criteria to make the distinction between productive and non-productive labor of value in the service sector. Thus, it intends to contribute to clarify the understanding of the labor theory of value in a field intercrossed with discussions and differentiated theoretical standpoints.

KEY wORDS: Labor theory of value. Labor. Productive and non-productive labor. Surplus-value.

\section{THÉORIE DE LA VALEUR ET DU TRAVAIL PRODUCTIF DANS LE SECTEUR DES SERVICES}

\section{Sadi Dal Rosso}

Il est difficile pour certaines interprétations de la théorie de la valeur-travail de définir le rôle et la place des activités de service quant à la production ou non de valeur. Ce problème s'amplifie dans la mesure où, pris dans une perspective historique, il est démontré que les services sont actuellement une importante source d'emplois. Les services ont traditionnellement été considérés comme des activités non-productives car, entre autres arguments, on estime qu'ils n'aboutissent pas à la matérialisation de marchandises ou à la production de nouvelles valeurs ou de plus-value. Le but de cet article est de se pencher sur cette question et de suggérer que certains services, qui répondent à des critères définis, peuvent être considérés comme producteur de valeur et de plus-value. On y analyse les catégories matérialité et immatérialité ainsi que celles du travail producteur et non producteur de valeur pour introduire ensuite des critères capables de faire la distinction entre travail producteur et non producteur de valeur dans le secteur des services. L'intention est de contribuer à clarifier la compréhension de la théorie de la valeur-travail sur un terrain semé de polémiques et de positions théoriques controversées.

Mots-CLÉs: Théorie de la Valeur-Travail. Services. Travail productif et non productif. Plus-value. Sadi Dal Rosso - Doutor em Sociologia. Professor do Departamento de Sociologia da Universidade de Brasília.
Pesquisador do CNPq, do Grupo de Estudos e Pesquisas para o Trabalho (GEPT) e da Rede de pesquisadores
sobre Associativismo e Sindicalismo dos Trabalhadores em Educação (Rede ASTE). Integra a linha de Pesquisa
Trabalho e Sociedade na UnB. Desenvolve pesquisas na área de tempos de trabalho, teoria do valor trabalho
e sindicalismo em educação. Publicações recentes: Duração do trabalho em todo o mundo. Tendências de
jornadas de trabalho, legislação e políticas numa perspectiva global comparada. Sociedade e Estado (UnB.
Impresso), v. 27, p. 183-191, 2012; Crise, convite para a ação e um Manifesto Comunista. Sociologias (UFRGS.
Impresso), v. 14, p. 338-350, 2012; Condições de Emergência do Sindicalismo Docente. Pro-Posições (UNICAMP.
Impresso), v. 23, p. 37-54, 2011; A intensificação do labor na sociedade contemporânea (São Paulo: Boitempo
Editorial, 2012). Associativismo e Sindicalismo em Educação. Organização e Lutas. Brasília: Paralelo 15,
2011. 366p. 